\title{
O estado de coisas inconstitucional no cenário de acesso ao aborto legal no brasil
}

The unconstitutional thing state at the legal abortion access scenario in

\author{
Brazil
}

\author{
Henrique Rosmaninho Alves 1
}

\begin{abstract}
RESUMO
O presente artigo faz uma análise do cenário existente no Brasil para garantir o acesso ao aborto legal às mulheres que tenham o direito de realizá-lo. Busca-se identificar se o quadro de infraestrutura e informações disponível para concretizar esse direito, bem como se o número de mulheres que deixam de ser atendidas anualmente configuraria o instituto do estado de coisas inconstitucional. Para tanto se investigou os dados relativos ao abortamento legal e inseguro no Brasil obtidos pelo grupo "Católicas pelo Direito de Decidir", pelo "Article 51", pela pesquisadora Débora Diniz e divulgados pelo Ministério da Saúde. Trata-se de uma pesquisa jurídicosociológico, bibliográfica, qualitativa, com emprego de raciocínio dedutivo. Ao final conclui-se que a perene precariedade ou inexistência completa de infraestrutura pública de saúde disponível para promover o acesso ao aborto legal e seguro, bem como a ausência de informações sobre os direitos sexuais e reprodutivos das mulheres por parte dos órgãos oficiais de saúde configura o estado de coisas inconstitucional e faz'se duas sugestões para reverter esse quadro.
\end{abstract}

PALAVRAS-CHAVE: Aborto legal. Direitos sexuais e reprodutivos. Estado de coisas inconstitucional.

\begin{abstract}
This paper analyzes the existing scenario in Brazil to ensure access to legal abortion for women who have the right to perform it. It seeks to identify whether the infrastructure and information framework available to realize this right, as well as whether the number of women who are not served annually would constitute the unconstitutional state of affairs institute. To this end, we investigated the data on legal and unsafe abortion in Brazil obtained by the group "Catholic for the Right to Decide", "Article 19", researcher Débora Diniz and released by the Ministry of Health. Sociological, bibliographical, qualitative, using deductive reasoning. In the end it is concluded that the perennial precariousness or complete lack of public health infrastructure available to promote access to legal and safe abortion, as well as the lack of information on the sexual and reproductive
\end{abstract}

\footnotetext{
1 Graduado em Direito pela Pontifícia Universidade Católica de Minas Gerais. Mestre em Direito Ambiental pela Escola Superior Dom Helder Câmara. Doutorando em Direito Constitucional pela Pontifícia Universidade Católica de Minas Gerais. Professor da Faculdade Iseib de Betim e no Instituto Minas de Educação e Cultura - IMEC. Advogado. Email: henrique_rosmaninhoalves@outlook.com
} 
rights of women by the official health bodies configures the unconstitutional state of affairs and two suggestions are made to reverse this picture.

KEYWORDS: Legal abortion; Sexual and reproductive rights;

Unconstitutional state of affairs.

\section{Introdução}

O presente estudo analisou o atual cenário de acesso ao aborto legal no Brasil, a estrutura de saúde disponível para realizar os procedimentos, a quantidade e qualidade de informações disponibilizadas pelos órgãos públicos de saúde e o processo de atendimento das mulheres que pretendem abortar nos serviços de saúde para viabilizar a concretização do direito ao abortamento legal e seguro.

Considerando todos esses fatores tem-se como objetivo geral identificar se o atual quadro do aparato de saúde existente para promoção do direito ao aborto legal caracteriza-se como estado de coisas inconstitucional.

Foram estabelecidos 6 objetivos específicos quais sejam: identificar a quantidade de abortos ilegais realizados anualmente no mundo e no Brasil; identificar a quantidade de mortes resultantes de abortos ilegais ocorridas anualmente no mundo e no Brasil; identificar a quantidade de abortos legais realizados anualmente no Brasil; identificar a quantidade de situações que se enquadram nas hipóteses de abortamento legal no Brasil anualmente nas quais a gestação é levada ao fim; identificar a quantidade de mulheres que anualmente no Brasil são internadas devidas a complicações decorrentes de abortamento inseguro; identificar a infraestrutura pública disponível para garantir o acesso ao aborto legal no Brasil.

Trata-se de uma pesquisa jurídico-sociológico, bibliográfica, qualitativa, com emprego de raciocínio dedutivo, cujo marco teórico foram os dados relativos ao abortamento legal e inseguro no Brasil obtidos pelo grupo Católicas pelo Direito de Decidir, pelo Article 51, pela pesquisadora Débora Diniz e divulgados pelo Ministério da Saúde.

A relevância da presente investigação deriva do fato de que anualmente estima-se que são realizados mais de 500 mil abortos inseguros no Brasil e mais de 1500 abortos legais, sendo que esta última cifra poderia chegar a 2700 apenas se 
considerar-se os casos de gestações levadas ao fim nas hipóteses em que o ordenamento jurídico pátrio permite o abortamento.

A verificação de que as mulheres de três estados da federação e de que quase a totalidade das mulheres residentes no interior do país não têm acesso a serviços de aborto legal demonstra também a relevância do presente estudo e sua possibilidade de colaborar com a divulgação de um cenário precário que perdura por mais de oito décadas e que necessita urgentemente ser revertido para efetivamente conseguir promover os direitos sexuais e reprodutivos das mulheres, notadamente o direito ao aborto legal e seguro.

No intuito de facilitar a compreensão do exposto, dividiu-se o presente estudo em três capítulos, sendo o primeiro destinado a realizar uma conceituação do aborto e demonstrar suas dimensões quantitativas mundiais; o segundo, expor o atual cenário fático e jurídico sobre o aborto no Brasil e o terceiro, identificar se o quadro existente de acesso ao aborto legal no Brasil caracteriza-se como estado de coisas inconstitucional.

\section{Aborto: conceito, evolução normativa histórica e dimensões mundiais}

O verbo abortar conforme o Dicionário Online de Português significa "Dar à luz antes do termo e em condições que não permitem a sobrevivência do feto: abortou um feto inviável" 2 .

O aborto pode ser espontâneo, quando involuntário, ou provocado, quando realizado voluntariamente, hipótese na qual se utiliza a nomenclatura "induzido", pode ser classificado como seguro ou inseguro a depender das condições em que for realizado.

A Organização Mundial da Saúde (OMS) define aborto inseguro como o procedimento utilizado para interromper uma gravidez, realizado por pessoas nãohabilitadas ou em ambiente não-adequado. (WHO, 2005)

A realização de abortos inseguros decorre principalmente do fato de este procedimento ser considerado crime em diversos países, o que leva as mulheres que pretendem realizá-lo a buscar locais clandestinos desprovidos de infraestrutura ou mesmo a praticarem o auto aborto.

2 Disponível em: <https://www.dicio.com.br/abortar/>. Acesso em: 29 jul. 2019. 
Convém destacar que a realização de aborto foi uma prática corriqueira em quase todas as sociedades e apenas no século XIX as nações ocidentais passaram a regulamentá-la, muitas das vezes, proibindo-a, principalmente por influência da Igreja Católica.

Isso porque o Papa Pio IX impôs a proibição absoluta do aborto em 1869, baseando-se na teoria da personificação imediata do feto, prevendo a pena de excomunhão (atualmente em vigor) a quem o praticar. (TALIB; CITELI, 2005, p.11)

Embora a prática do aborto tenha sido criminalizada em vários países e discriminalizada em tantos outros, fato é que a criminalização nunca foi capaz de coibir a sua prática, tendo como principal efeito apenas levar as mulheres a praticálo na clandestinidade, em condições insalubres.

O estudo denominado "Abortamento inseguro: fatos e números" realizado por Mesce e Sines em 2006 apontou que são feitos aproximadamente 19 milhões de abortos inseguros no mundo anualmente, os quais acarretam 68 mil mortes, o que representa 13\% dos óbitos maternos. (MESCE; SINES, 2006)

No mesmo sentido a Organização Mundial da Saúde estimou em 2008 que ocorreram 47 mil mortes devido a abortos inseguros no mundo, o que equivalia à época a 13\% das mortes maternas no mundo. (MARTINS, 2017. p.2).

Vale ressaltar que tais números correspondem apenas aos abortos inseguros, não computando os realizados em locais adequados.

Atualmente quase todos os países desenvolvidos do planeta permitem o aborto, como é o caso da quase totalidade dos países europeus, dos EUA, do Canadá, do Japão, da China, de parte do território australiano, etc.

Nos países desenvolvidos a grande maioria dos abortamentos (92\%) ocorre de maneira segura, ao passo que quase a totalidade dos abortamentos (97\%) nos países em desenvolvimento acontecem de forma insegura. (CECATTI, 2010, p.106)

Grande parte dos países, principalmente os em desenvolvimento ou subdesenvolvidos ainda preveem o aborto como crime, estabelecendo exceções a casos específicos, como risco de morte da mãe, má-formação fetal, gestação decorrente de estupro, risco a saúde mental da mãe ou fatores socioeconômicos.

O Brasil possui uma legislação consideravelmente restritiva no que tange ao direito ao aborto, permitindo sua prática apenas em três circunstâncias: gestação decorrente de estupro, risco de morte da mãe e anencefalia fetal. 
No intuito de tornar o presente estudo mais didático, abordar-se-á adiante especificamente o cenário do aborto no Brasil.

\section{0 atual cenário fático-jurídico do aborto no Brasil}

O aborto no Brasil é previsto como crime no artigo 124 do Código Penal, o qual estabelece pena de detenção de um a três anos à mulher que o praticar. (BRASIL, 1940).

O Código Penal prevê, no entanto, duas situações em que a prática do aborto não é punível em seu artigo 128, quais sejam: o aborto necessário, quando não há outro meio de salvar a vida da gestante e o aborto no caso de gravidez resultante de estupro.

Estas duas hipóteses são permitidas no Brasil desde 1940, data em que entrou em vigor o Código Penal, mas em 2012, por intermédio da Arguição de Descumprimento de Preceito Fundamental 54 - ADPF 54, foi descriminalizado o aborto nos casos de anencefalia fetal, sendo estas atualmente as únicas três hipóteses em que a prática do aborto não é crime no país.

Não obstante o rigorismo da legislação pátria o abortamento é uma realidade constante no país, constituindo uma das cinco principais causas de morte materna.

Estudo denominado "Pesquisa Nacional do Aborto" realizado em 2010 e em 2016 pelos pesquisadores Débora Diniz, Marcelo Medeiros e Alberto Madeiro, identificou que aproximadamente 416 mil mulheres abortaram no país em 2015, sendo que 19\% das mulheres de 40 anos já realizaram ao menos um aborto, ou seja, quase uma em cada cinco mulheres. (DINIZ; MADEIRO; MEDEIROS, 2017, p.656).

O mesmo estudo aponta tanto no realizado em 2010 quanto no de 2016 que cerca de metade das mulheres precisou ser internada para finalizar o aborto. (DINIZ; MADEIRO; MEDEIROS, 2017, p.656) 3 .

Conforme dados do DATASUS, no ano de 2017, foram registradas 177.464 curetagens pós-abortamento (um mecanismo de raspagem da parte interna do útero) e outras 13.046 esvaziamentos de útero por aspiração manual intrauterina

\footnotetext{
${ }_{3}$ Cerca de metade das mulheres precisou ser internada para finalizar o aborto: $48 \%$ (115) das mulheres
} foram internadas no último aborto. (DINIZ; MADEIRO; MEDEIROS, 2017, p.656). 
(AMIU), o que somado indica que houve 190.510 internações por complicações resultantes de aborto inseguro. (FERNANDES, 2019)

O elevado número de abortos inseguros no Brasil acarreta na morte de mais de 200 mulheres anualmente, sendo a quinta causa de morte materna do país, segundo dados do Ministério da Saúde.

Embora a gravidade do cenário do aborto no Brasil demande a realização de maiores estudos e indubitavelmente da descriminalização da prática do mesmo e consequente acolhimento dessas mulheres nos estabelecimentos oficiais de saúde, o presente estudo debruça-se apenas sobre os casos em que o aborto é permitido no país, e visa identificar se o direito ao abortamento é efetivamente garantido as mulheres que são suas titulares e em que condições.

\subsection{0 acesso ao aborto legal no Brasil}

Conforme dito anteriormente o aborto nos casos de risco de morte da mãe e de gestação decorrente de estupro é permitido no Brasil desde 1940.

Ocorre que foi apenas em 1989 foi inaugurado o primeiro serviço público de atenção à violência sexual contra mulheres e à realização de abortos no país, no Hospital Municipal Arthur Ribeiro de Saboya, conhecido como Hospital do Jabaquara, localizado na cidade São Paulo.4 (TALIB; CITELI, 2005).

Nota-se que durante 50 anos as mulheres brasileiras que se enquadravam nas hipóteses em que o aborto é permitido não dispuseram de atendimento publico gratuito voltado a garantir-lhes a execução de seu direito.

A ampliação dos serviços públicos de acesso a aborto seguro no Brasil sofreu forte resistência. Em 1992, por exemplo, foi anunciada a previsão de inauguração de serviço dessa natureza no Hospital Ermelino Matarazzo, na zona leste de São Paulo, serviço que nunca entrou em funcionamento. (TALIB; CITELI, 2005, p.15).

\footnotetext{
4 Quando da implantação do serviço no Hospital do Jabaquara, a administração municipal de São Paulo, conhecendo a delicadeza do assunto, cercou-se de cuidados e beneficiou-se de uma conjunção de elementos favoráveis. A prefeita Luiza Erundina nomeara Secretário Municipal de Saúde o médico Eduardo Jorge, sensível às demandas das mulheres, que, por sua vez, indicou a médica feminista Maria José Araújo para o Programa de Saúde da Mulher; esta atribuiu a Edna Rolland, feminista negra, a responsabilidade de coordenar uma comissão responsável pela implantação do serviço em hospitais municipais... Enfrentando resistências políticas internas (como a do então Secretário Municipal de Negócios Jurídicos Hélio Bicudo, ou mesmo de profissionais de próprio hospital) e externas, finalmente o serviço foi inaugurado em 12 de agosto de 1989... (TALIB; CITELI, 2005, p.13,14).
} 
No ano de 1998 o Ministério da Saúde expediu a Norma Técnica para "Prevenção e tratamentos dos agravos resultantes da violência sexual contra mulheres e adolescentes", destinada a orientar os serviços de atendimento às vítimas de violência e ao aborto permitido em lei. Nessa ocasião ainda haviam apenas 8 serviços de aborto legal funcionando no país.

Referida Norma Técnica exigia, para garantir o acesso ao aborto legal, a apresentação de cópia do Boletim de Ocorrência (BO); a autorização da gestante ou de seu responsável legal; o registro no prontuário médico das consultas realizadas, da decisão da equipe multidisciplinar e dos resultados dos exames clínicos e laboratoriais; além da informação à mulher de que ela poderia ser responsabilizada criminalmente caso suas declarações fossem falsas.

Referidas exigências foram mitigadas nas revisões da mencionada Norma Técnica, realizadas em 2005 e em 2012, momento no qual o consentimento da mulher passou a ser suficiente para o acesso ao aborto legal, não havendo mais que se apresentar BO, ou investigar o testemunho da mulher.

Não obstante estudo realizado por Débora Diniz, Vanessa Canabarro Dios, Miryan Mastrella e Alberto Pereira Madeiro, intitulado "A verdade do estupro nos serviços de aborto legal no Brasil”, constatou que é comum os serviços fazerem uma verificação do nexo de causalidade entre o discurso da vítima e o período gestacional, a fim de verificar se aquela gravidez é realmente resultante da violência sofrida. (DINIZ; et al, 2014).

É o que se verifica da fala de alguns profissionais da saúde integrantes dos serviços de aborto legal que foram entrevistados pelos pesquisadores:

No caso do aborto legal, não tem a exigência do Boletim de Ocorrência mas tem que ter o nexo causal, tem que bater a história da paciente com a do tempo da gravidez... (DINIZ, et al, 2014, p. 294).

[...] porque, como a gente sabe que não tem a exigência do $\mathrm{BO}$, mas só que o Ministério Público depois não quer saber. Se você indicou um aborto que não houve nexo causal, o Ministério Público vai para cima do médico, ele não vai pra cima da paciente que veio procurando o aborto legal... (DINIZ, et al, 2014, p. 295).

A exigência de alvará judicial para promover o aborto de feto anencefálico também foi constatada em alguns serviços de aborto legal, em investigações da 
ONG Católicas pelo Direito de Decidir. Tal fato talvez decorre do modo como ocorreu a descriminalização do aborto em caso de anencefalia fetal no Brasil.

O primeiro caso de interrupção de gestação de feto anencefálico5 no Brasil ocorreu em 1992, ocasião em que um juiz da cidade de Londrina/PR concedeu autorização judicial para a realização do procedimento. No ano seguinte o Instituto de Medicina Fetal e Genética Humana conseguiu autorização judicial para a realização de aborto num caso de anomalias múltiplas do sistema nervoso do feto, na cidade de São Paulo. (TALIB; CITELI, 2005).

Até o ano de 1999 o grupo “Católicas pelo Direito de Decidir” identificou 263 processos judiciais requerendo direito ao aborto em casos de anomalia fetal grave, dentre os quais 250 obtiveram a autorização. (TALIB; CITELI, 2005).

No ano de 2004 a Confederação Nacional dos Trabalhadores da Saúde promoveu a Arguição de Descumprimento de Preceito Fundamental n ${ }^{0} 54$ perante o Supremo Tribunal Federal pleiteando a descriminalização da interrupção da gestação de fetos anencefálicos, e, em 2012 o pedido fora julgado procedente, criando-se mais uma hipótese de aborto legal no Brasil.

Os serviços de aborto legal passaram então a exigir alvará judicial para realizar o procedimento de interrupção da gestação por motivo de anencefalia fetal e posteriormente referida exigência foi eliminada, bastando a apresentação de exames médicos atestando referida anomalia.6

Importante salientar que o item 8.25 do Relatório da Conferência Internacional sobre População e Desenvolvimento realizada no Cairo em 1994:

8.25 [...]Em circunstâncias em que o aborto não contraria a lei, esse aborto deve ser seguro. Em todos os casos, as mulheres devem ter acesso a serviços de qualidade para o tratamento de complicações resultantes de aborto. Os serviços de orientação pós-aborto, de educação e de planejamento familiar devem ser de imediata disponibilidade, o que ajudará também a evitar repetidos abortos. (ONU, 1994).

\footnotetext{
5 A interrupção da gestação de feto anencefálico não se trata propriamente de um aborto, afinal o feto não possui a menor condição possuir vida e a nosso ver para a caracterização do aborto é necessária essa potencialidade do feto.

${ }_{6}$ O Conselho Federal de Medicina, por meio da Resolução n. 1.989, de 10 de maio de 2012, estabeleceu os critérios para a antecipação terapêutica do parto de feto anencéfalo: "duas fotografias, identificadas e datadas, uma com a face do feto em posição sagital; a outra, com a visualização do polo cefálico no corte transversal, demonstrando a ausência da calota craniana e de parênquima cerebral identificável; laudo assinado por dois médicos, capacitados para tal diagnóstico".
} 
Viu-se que até 1998 o Brasil possuía apenas oito serviços de aborto legal em funcionamento. Nos anos seguintes houve uma ampliação do número de serviços, embora ainda muito aquém do necessário. (TALIB; CITELI, 2005).

Em 2005 o grupo Católicas pelo Direito de Decidir publicou o DOSSIÊ "Serviços de aborto legal em hospitais públicos brasileiros (1989-2004)" no qual identificou 37 serviços em funcionamento e que 5 estados brasileiros não dispunham de serviço de aborto legal, quais sejam: Roraima, Amapá, Tocantins, Piauí e Mato Grosso do Sul.7 (TALIB; CITELI, 2005).

Esse mesmo estudo identificou que os quatro serviços disponíveis na região norte se localizavam em capitais de estados, bem como os três da região centrooeste. Dos sete serviços disponíveis na região sul, seis se situavam em Porto Alegre (4) e Curitiba (2) e dos 12 serviços disponíveis na região sudeste 7 estão nas capitais, sendo a cidade de Betim/MG a única do interior do país com mais de um serviço. (TALIB; CITELI, 2005).

\section{Figura 1 - Distribuição dos serviços de aborto legal no Brasil}

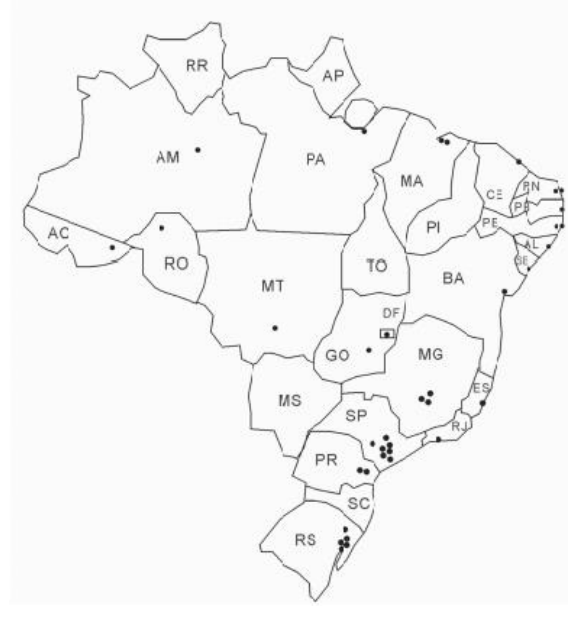

Fonte: (TALIB; CITELI, 2005, p.52)

TABELA 1 - Serviços de aborto legal por ano de implantação, segundo regiões do país 


\begin{tabular}{lcccccc}
\hline Ano de implantacio & Total de serviços & Norte & Nordeste & Sudeste & Sul & Centro-Oeste \\
\hline $1989-1994$ & 4 & 0 & 0 & 3 & 0 & 1 \\
\hline 1996 & 4 & 1 & 2 & 0 & 0 & 1 \\
\hline 1998 & 6 & 1 & 1 & 3 & 1 & 0 \\
\hline $1999-2000$ & 9 & 0 & 5 & 3 & 1 & 0 \\
\hline $2001-2002$ & 6 & 1 & 0 & 1 & 4 & 0 \\
\hline $2003-2004$ & 7 & 1 & 3 & 2 & 0 & 1 \\
\hline Náo informado & 1 & 0 & 0 & 0 & 1 & 0 \\
\hline Total $(\mathbb{N})$ & 37 & 4 & 11 & 12 & 7 & 3 \\
\hline Total $(\%)$ & $100 \%$ & $11 \%$ & $30 \%$ & $32 \%$ & $19 \%$ & $8 \%$ \\
\hline
\end{tabular}

Fonte: (TALIB; CITELI, 2005, p.54)

Em 2009 o Ministério da Saúde apontou a existência de 60 serviços de aborto legal no país. 8

No ano de 2018, levantamento realizado pelo instituto ARTICLE 19 verificou que das 176 instituições cadastradas no Ministério da Saúde e na Confederação de Estabelecimentos de Saúde - CNES como locais que realizam abortos nas três hipóteses permitidas pelo ordenamento jurídico, apenas 76 confirmaram a oferta do serviço. Esse levantamento identificou que os estados do Amapá de Rondônia e de Roraima ainda não possuem serviços públicos de aborto legal. (ARTICLE 19, 2018).

Embora apenas 3 estados da federação não possuam serviço de aborto legal, no ano de 2017 o Hospital Pérola Byington concentrou 25\% dos abortos legais registrados no país (400 de 1590), e atendeu mulheres de todas as regiões do país, o que denota que apesar de existirem serviços em funcionamento nas outras regiões do país há dificuldade das mulheres em acessá-los. (PESSOA, 2019).

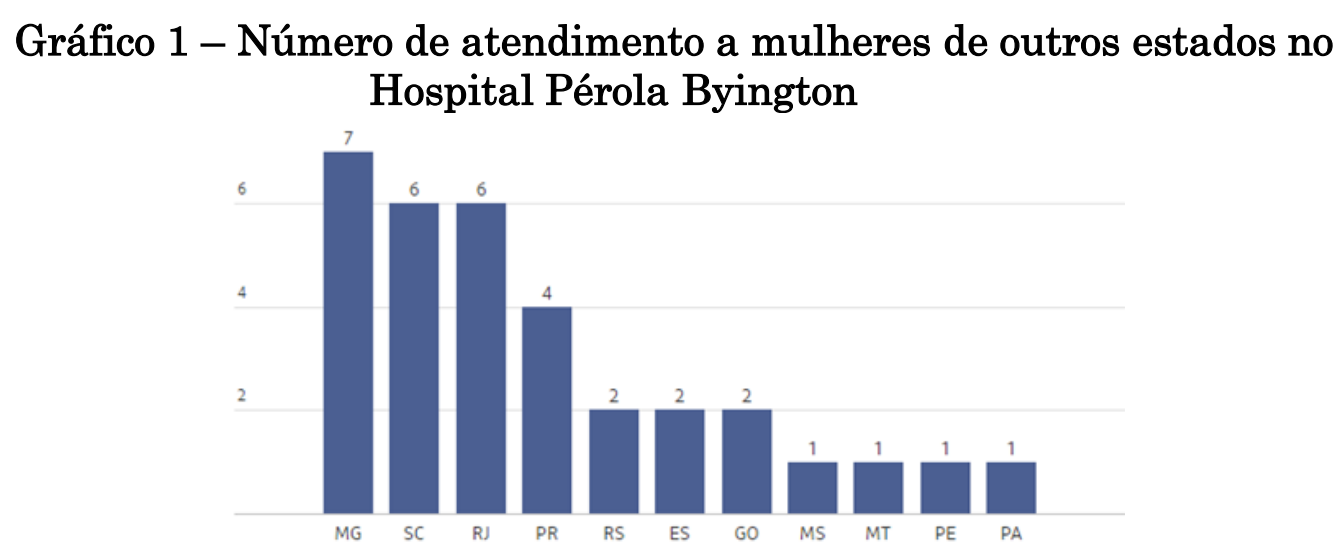

Fonte: (PESSOA, 2019)

8 Brasil. Ministério da Saúde. Hospitais e serviços de referência em atendimento para mulheres e adolescentes em situação de violência sexual - Brasil [internet]. 2009. Acesso: mai 2015. Disponível em: $<$ http:// portal.saude.gov.br/portal/arquivos/pdf/atsm_res_serv_At_viol_sexual_2009.pdf $>$. 
Tal dificuldade pode ser atribuída a falta de informações sobre o aborto legal no país. De modo geral o acesso ao aborto legal para ser concretizado precisa de dois fatores: a) infraestrutura pública disponível para realizar o procedimento e b) disponibilidade de informações em meios acessíveis e conscientização da população sobre o direito ao aborto legal.

O primeiro desses pontos já fora analisado no presente estudo e infelizmente é notória a defasagem de infraestrutura pública disponível para realizar tais procedimentos no Brasil.

Já no que tange ao segundo aspecto “disponibilidade de informações” é importante destacar que a Conferência Internacional de Direitos Humanos (Teerã, 1968), estabeleceu que todas as pessoas têm direito a receber educação e obter informações adequadas referentes aos seus direitos sexuais e reprodutivos. (ARTICLE 19, 2018, p.7).

O instituto ARTICLE 19 realizou estudo no Brasil e apontou a ausência de informação como um dos principais fatores que dificultam a concretização do direito ao aborto legal no Brasil.

[...] a população não sabe em quais estabelecimentos o procedimento pode ser feito. Não existe uma lista pública, de fácil acesso e amplamente publicizada dos hospitais públicos e maternidades que de fato oferecem o serviço. (ARTICLE 19, 2018, p.7).

O estudo realizado em 2018 pelo instituto Article 19 e denominado "Breve Panorama Sobre Aborto Legal e Transparência no Brasil" avaliou os sites do Ministério da Saúde, das Secretarias Estaduais de Saúde dos 26 estados e do Distrito Federal e das 26 capitais de estados.

Este estudo identificou que dentre os órgãos estaduais 20 deles não informam em quais situações o aborto é permitido no Brasil, quatro informam apenas algumas hipóteses e apenas três informam sobre todas as situações (Goiás, Paraná e Rio Grande do Sul). No que tange aos órgãos de saúde das capitais, 22 deles não informam em quais situações o aborto é permitido e apenas o site da Secretaria Municipal de Saúde de Palmas informa todas as hipóteses de aborto legal vigentes no país. Já o site do Ministério da Saúde não informa diretamente as hipóteses de aborto legal, mas apenas mantém uma cartilha disponível para 
download que contém os casos em que o abortamento é legalizado no Brasil. (ARTICLE 19, 2018).

O mesmo estudo constatou ainda que 25 estados não publicam lista de serviços ou unidades hospitalares que realizam o procedimento de aborto legal, assim como 18 capitais de estados. (ARTICLE 19, 2018).

A defasagem de informações acerca do direito ao aborto legal é seguramente uma das razões para a grande quantidade de mulheres que tinham direito a realizar o aborto legal deixarem de fazê-lo.

A Dra. Maria de Fátima Marinho, então diretora do Departamento de Vigilância de Doenças e Agravos não Transmissíveis e Promoção da Saúde, em audiência pública realizada na Câmara dos Deputados em dezembro de 2017 informou que entre 2011 e 2016, um total de 4.262 adolescentes de 10 a 19 anos tiveram uma gestação resultante de estupro em que houve o nascimento do bebê. (FERNANDES, 2019). Tal número evidencia que por ano, aproximadamente 700 jovens brasileiras vítimas de estupro tem o direito ao aborto negado pelo sistema.

Outro dado que evidencia que a ausência de informação dificulta o exercício do direito ao aborto legal no Brasil não é o contatado no estudo "Estupro no Brasil: uma radiografia segundo os dados da Saúde", desenvolvido pelo Ipea (Instituto de Pesquisas Econômicas Aplicadas) em 2014. (CERQUEIRA; COELHO, 2014)

Referido estudo aponta que 7,1\% dos estupros ocorridos no Brasil resultaram em gravidez, segundo dados do SUS de 2011. Dentre as vítimas adultas 19,3\% realizaram aborto, ao passo que apenas $5,0 \%$ o fizeram entre as adolescentes e $5,6 \%$ entre as crianças. (CERQUEIRA; COELHO, 2014).

A maior quantidade de informações que os adultos possuem, bem como a ausência de influência externa para realizar a opção pelo aborto, podem ser indicativos de tamanha discrepância entre os percentuais de abortos legais ocorridos entre vítimas de estupro adultas e crianças e adolescentes.

No que concerne ao aborto legal nos casos de anencefalia fetal, conforme dados apresentados pela Dra. Maria de Fátima Marinho, entre 2006 e 2016 houve uma variação de 420 a 500 nascimentos de fetos anencefálicos no país. (FERNANDES, 2019)

O número de abortos legais praticados no Brasil anualmente, conforme dados do Ministério da Saúde varia em torno de 1700, sendo que no ano de 2017 foram praticados 1636 abortos legais. (FERNANDES, 2019). 


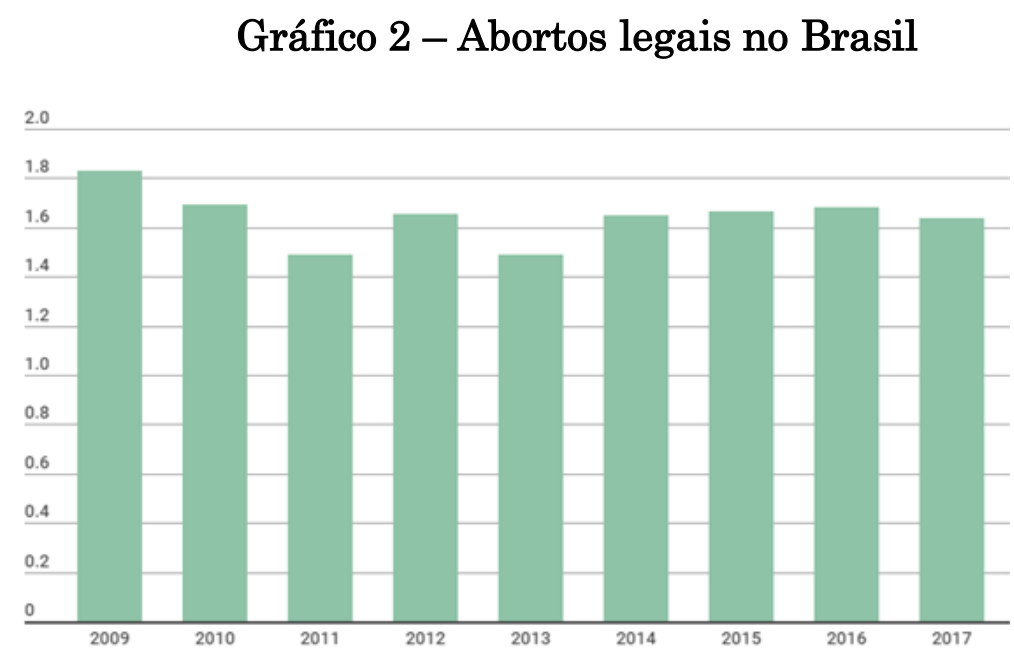

Fonte: (FERNANDES, 2019)

Somados às aproximadamente 700 gestações anuais decorrentes de estupro com as mais de 400 gestações de fetos anencefálicos, tem־se que mais de 1100 mulheres que teriam direito ao aborto legal no Brasil não o fazem, fora a subnotificação habitual nesses casos.

A ausência de informações sobre os direitos sexuais e reprodutivos, somada à ausência de infraestrutura pública disponível para realizar o aborto legal são os principais fatores identificados para a não concretização do aborto legal no Brasil. Outros fatores apontados pelos pesquisadores habituais sobre o tema são a exigência irregular de documentos para acessar o direito ao aborto legal (como Boletim de Ocorrência, laudo do IML, alvará judicial) e a objeção de consciência dos médicos.

O cenário de atendimento às mulheres detentoras do direito ao aborto legal no Brasil caracteriza o que convencionou-se denominar de "estado de coisas inconstitucional", como verificar-se-á adiante.

\section{A caracterização do estado de coisas inconstitucional no que tange ao cenário de acesso ao direito ao aborto legal no Brasil}

O Estado de Coisas Inconstitucional é uma tese criada pela Corte Constitucional da Colômbia na qual declara-se a existência de uma violação massiva de direitos fundamentais ocasionadas por falhas sistêmicas de determinada ação do governo. 
A Corte Constitucional da Colômbia definiu o Estado de Coisas Inconstitucional como "la declaratória que hace la Corte Constitucional, cuando se constata la vulneración repetida y constante de derechos fundamentales que afectan a multitud de personas, cuya solución requiere la intervención de distintas entidades para atender problemas de orden estructural”. (COLÔMBIA, 2004).

Em 1997 a Corte Constitucional da Colômbia - CCC, em decisão de teor inédito inovou sua jurisprudência e declarou o Estado de Coisas Inconstitucional na Sentencia de Unificación $n^{\circ} 559$. No caso em questão, os professores da rede pública de ensino dos municípios de Marí ala Baja e Zambrano arguiram que não receberam os benefícios previdenciários por não terem sido filiados a um banco ou fundo de previdência social, mesmo tendo contribuído com 5\% de seus salários para tal finalidade. Os Municípios em comento deixaram de filiar seus professores ao Fondo Nacional de Prestaciones Sociales del Magisteri e utilizaram os valores oriundos das contribuições destes para custear outras despesas, violando assim o direito à vida, à saúde e à segurança social destes profissionais. (ROSENDA, 2017).

Diante de tal cenário a Corte Constitucional então declarou o Estado de Coisas Inconstitucional e determinou que os municípios corrigissem a inconstitucionalidade em prazo razoável.

Logo em 1998 a CCC na Sentencia T-068 declarou novamente o Estado de Coisas Inconstitucional em face da inércia da Caja Nacional de Previsión Social em responder os pedidos de reconhecimento e revalidação das pensões e verbas previdenciárias. A demora na resposta a tais pedidos acarretou no ajuizamento de mais de 30.000 ações contra a entidade. A Corte Constitucional entendeu que a situação narrada além de afetar direitos individuais, afetava também todo o Poder Judiciário que ficou congestionado com a apreciação de tantas demandas, o que prejudicava o exercício de sua função. (ROSENDA, 2017).

Ainda em 1998 a Corte Constitucional da Colômbia reconheceu e declarou o Estado de Coisas Inconstitucional em mais duas oportunidades, na Sentencia de Unificación $n^{\circ} 250$ e na Sentencia de Tutela T-153. Referidos casos referiram-se respectivamente a inobservância da exigência de realização de concurso público para tabelião e a precariedade do sistema carcerário face a superlotação das penitenciárias. (ROSENDA, 2017).

Em 2004 a CCC novamente declarou o Estado de Coisas Inconstitucional, dessa vez em face do quadro caótico de deslocamento forçado de pessoas em razão 
da violência urbana e da atuação das Forças Armadas Revolucionárias da Colômbia - FARC. Nesta oportunidade a Corte ordenou a formulação de políticas públicas, a elaboração de leis e de um marco regulatório hábil a proteger os direitos envolvidos. (ROSENDA, 2017).

Embora tenha sido declarado reiteradas vezes ao longo dos últimos vinte e dois anos, o Estado de Coisas Inconstitucional possui diversos pressupostos para sua caracterização, os quais devem estar totalmente presentes no caso em tela para viabilizar seu reconhecimento.

Segundo ensinamentos de Carlos Alexandre de Azevedo Campos são pressupostos essenciais para a caracterização do ECI: a) a existência de um cenário de violação massiva, reiterada, generalizada e sistemática de direitos fundamentais, que atinja um número elevado de pessoas; b) a ausência de coordenação entre as medidas legislativas, administrativas e orçamentárias que acarrete a inefetividade destas e exija uma mudança estrutural para cessar com as violações de direitos fundamentais constatadas; c) a duradoura inércia das autoridades públicas e; d) a possibilidade de congestionamento do Poder Judiciário em caso de ajuizamento de ação individual por todos aqueles que tiveram seus direitos violados. (CAMPOS, 2015).

No Brasil o ECI somente foi declarado uma única vez pelo Supremo Tribunal Federal, no bojo da Arguição de Descumprimento de Preceito Fundamental ADPF n 347 ajuizada pelo Partido Socialismo e Liberdade - PSOL, na qual o partido postulou o reconhecimento do ECI em face da violação massiva de direitos fundamentais da população carcerária do país ocasionada pelas condições degradantes do sistema prisional, como a superlotação e a precariedade das instalações prisionais

No caso em análise a medida cautelar requerida foi parcialmente deferida, determinando-se aos juízes e tribunais que realizassem audiências de custódia no prazo máximo de 90 dias, com o comparecimento do preso perante a autoridade judiciária no prazo máximo de 24 horas, bem como determinou à União que liberasse "o saldo acumulado do Fundo Penitenciário Nacional para utilização com a finalidade para a qual foi criado, abstendo-se de realizar novos contingenciamentos". (BRASIL, 2015).

Não obstante só tenha sido declarado uma vez, acredita-se que há no Brasil diversos outros casos passíveis de caracterização do Estado de Coisas 
Inconstitucionais, como ocorre com os reincidentes rompimentos de barragens no Brasil e com o cenário de acesso ao aborto legal no país.

No que tange ao quadro existente para realização do aborto legal no país, este cumpre de todos os pressupostos essenciais de caracterização do Estado de Coisas Inconstitucional.

O primeiro dos pressupostos essenciais do ECI é a existência de um cenário de violação massiva, reiterada, generalizada e sistemática de direitos fundamentais, que atinja um número elevado de pessoas. $\mathrm{O}$ atual quadro de ausência de infraestrutura para realização de aborto legal no Brasil atinge anualmente de maneira direta mais de 1100 mulheres (considerando-se as gestações decorrentes de estupro e de anencefalia fetal) e indiretamente/potencialmente milhões de mulheres que residem em localidades desprovidas do serviço público de aborto legal, visto que estes são apenas 37 no país e estão localizados em sua grande maioria nas capitais.

Todas as mulheres dos estados de Roraima, Rondônia e Amapá inclusive estão desprovidas deste serviço e são afetadas, tendo sistematicamente seu direito fundamental à saúde violado.

O segundo pressuposto essencial é a ausência de coordenação entre as medidas legislativas, administrativas e orçamentárias que acarrete a inefetividade destas e exija uma mudança estrutural para cessar com as violações de direitos fundamentais constatadas. O cumprimento de tal requisito denota da completa ausência de iniciativa legislativa relativa ao tema e da permanente precariedade da infraestrutura disponível para realização de abortos legais nos serviços públicos de saúde no país, bem como também pela insuficiência de informações dos órgãos públicos de saúde sobre o direito ao aborto legal no país.

Basta verificar que o primeiro serviço público de aborto legal no país só foi inaugurado 49 anos após o Código Penal (que previu as hipóteses em que o aborto não é punível), até 2008 existiam apenas 8 serviços em funcionamento, no ano de 2005 apenas 37 serviços funcionavam e no ano de 2018 apenas 76 serviços funcionavam, sendo que três estados da federação ainda não possuíam tais serviços e outros sete apenas na capital.

As medidas legais são inexistentes e as administrativas se mostraram insuficiente para mudar o cenário de insegurança e lesão a direitos fundamentais 
das mulheres detentoras do direito ao aborto legal, ou mesmo das mulheres em idade fértil de modo geral, visto que são potenciais utilizadores dos serviços.

O terceiro pressuposto essencial para concretização do ECI é a duradoura inércia das autoridades públicas para resolver o problema. Tal fato pode ser observado pela manutenção do quadro de poucos serviços públicos de abortos legais disponíveis no Brasil ao longo das últimas oito décadas. Vê-se que ainda existem três estados que não possuem um serviço sequer, o que acarreta que as mulheres que detenham o direito ao aborto que neles residam tenham que viajar milhares de quilômetros para concretizar seu direito, assim como tantas outras milhares de mulheres residentes no interior do país, visto que a maioria dos serviços situam-se nas capitais dos estados.

Por fim, o derradeiro requisito para a existência do ECI é a possibilidade de congestionamento do Poder Judiciário em caso de ajuizamento de ação individual por todos aqueles que tiveram seus direitos violados.

Esse requisito no caso em tela pode ser demonstrado da seguinte forma: se cada uma das mais de 1100 mulheres que anualmente têm direito a realizar o aborto legal e não o fazem, ingressarem com ações judiciais requerendo o direito a fazê-lo, seja pleiteando o custeio dos valores necessários para providenciar a viagem, hospedagem e transporte a locais em que há o serviço, ou pleiteando a própria criação do serviço em suas cidades, ou até mesmo pleiteando dano moral porque tiveram que levar a cabo tal gestação, somadas às 1700 mulheres que fazem abortos legais anualmente e que são submetidas a exigências irregulares ou a procedimentos que atentem contra sua moral durante o processo de acesso ao abortamento nos serviços e que também podem ingressar com ações judiciais, teríamos anualmente 2700 ações judiciais, as quais poderiam envolver uma multiplicidade de pedidos e de Réus (União, Estados, Municipios e profissionais da saúde), fora a conhecida subnotificação existentes nos casos de estupro.

Somadas essas circunstâncias poderia se atingir facilmente a cifra de 10 mil ações em três anos.

Face ao exposto concebe-se que a permanente e elevada violação a direitos fundamentais decorrentes da permanente precariedade da infraestrutura existente para prestar atendimento ao aborto legal no Brasil e da ausência de informações pelos órgãos oficiais de saúde caracteriza o Estado de Coisas 
Inconstitucional, sendo cabível sua declaração pelo STF, caso provocado para tanto.

Cabe ressaltar que há contundentes críticas à declaração do Estado de Coisas Inconstitucionais na doutrina brasileira, as quais merecem destaque em momento oportuno. Não obstante acredita-se que tal momento não é no bojo deste estudo, de modo que objetiva-se com a presente pesquisa identificar a possibilidade de enquadramento do atual cenário de acesso ao aborto legal no Brasil como Estado de Coisas Inconstitucional e não a pertinência jurídica deste instituto.

\subsection{Proposições para sanar o estado de coisas inconstitucional decorrente da massiva lesão de direitos fundamentais ocasionadas pela precariedade da infraestrutura e pela ausência de informações relacionadas ao aborto legal no Brasil}

A simples declaração do Estado de Coisas Inconstitucional não é capaz, por si só, de afastar o cenário de massiva e contínua lesão a direitos fundamentais da população, seja em qual caso este seja declarado.

Dessa forma, a adoção de medidas concretas deve ser determinada pelo Poder Judiciário, como a elaboração de políticas públicas pelo Poder Executivo e a edição de leis pelo Poder Legislativo.

Sendo assim, no intuito de contribuir para a superação do atual deplorável cenário de acesso ao direito ao abortamento legal no Brasil, aponta-se como sugestões:

a) A elaboração de uma nova Norma Técnica do Ministério da Saúde sobre o aborto legal no Brasil, prevendo as três hipóteses de abortamento legal, e que preveja de maneira cristalina ser exigível apenas o testemunho da mulher nos casos de estupro, a comprovação por exames da anencefalia fetal nos casos de aborto por esse motivo, ou o laudo de um médico atestando o risco de morte da gestante.

b) A criação de um plano nacional de acesso ao abortamento seguro que contemple três vertentes:

1 Ampliação de infraestrutura: no primeiro ano a inauguração de serviços de aborto legal nos três estados que ainda não o possuem, e posteriormente de maneira 
paulatina a criação de serviços em todas as cidades com população acima de 250 mil pessoas.

2 Ampliação das informações constantes nos órgãos oficiais de saúde de modo a tornar obrigatório que todos os Estados e Municípios brasileiros mantenham sites de suas secretarias de saúde no qual contenha informações sobre o direito ao aborto seguro.

3 Criação de um plano de conscientização nacional sobre o aborto seguro que atue em duas frentes: uma relativa aos profissionais da saúde e outra a população de modo geral.

Essa terceira vertente poderia ser concretizada através da disponibilização de cursos obrigatórios para os profissionais da saúde pública do país, bem como da inclusão do tema nas ementas das disciplinas dos cursos técnicos e de graduação da área da saúde, bem como da realização de cursos voltados a promover a conscientização do tema nas escolas públicas e particulares, preferencialmente na semana do dia internacional da mulher.

\section{Conclusão}

A execução da pesquisa proposta deu-se com base na leitura de diversos artigos e estudos sobre o tema e através da análise de dados oficiais divulgados pelo Ministério da Saúde.

Todos os seis objetivos específicos foram alcançados e expostos nos dois primeiros capítulos do artigo.

Verificou-se que há no Brasil uma permanente precariedade da estrutura de saúde pública disponível para garantir o acesso ao aborto legal, a qual já perdura por mais de oito décadas. A ausência de infraestrutura adequada somada à ausência de informações sobre o direito ao aborto legal são as características mais marcantes do quadro de acesso ao aborto legal no Brasil e provavelmente as principais responsáveis por anualmente milhares de mulheres não conseguirem ter respeitados os seus direitos sexuais e reprodutivos, notadamente o direito ao aborto legal e seguro.

Por todas essas circunstâncias de precariedade ou completa ausência de infraestrutura de saúde pública disponível, de ausência de informações sobre os direitos sexuais e reprodutivos das mulheres, de inadequação da postura dos 
profissionais de saúde ao proceder ao atendimento das mulheres titulares de direito ao aborto legal nos serviços públicos destinados à sua realização e do elevado número de mulheres que anualmente não conseguem concretizar o direito ao aborto legal e seguro no país, tem-se que caracterizado está o estado de coisas inconstitucional.

Dessa forma de modo derradeiro, no intuito de sanar o estado de coisas inconstitucionais verificado, faz-se duas sugestões, quais sejam: a elaboração de uma nova Norma Técnica do Ministério da Saúde sobre o aborto legal no Brasil, prevendo as três hipóteses de abortamento legal, e que preveja de maneira cristalina ser exigível apenas o testemunho da mulher nos casos de estupro, a comprovação por exames da anencefalia fetal nos casos de aborto por esse motivo, ou o laudo de um médico atestando o risco de morte da gestante; e a criação de um plano nacional de acesso ao abortamento seguro que contemple três vertentes (1 ampliação de infraestrutura; 2 ampliação das informações constantes nos órgãos oficiais de saúde; 3 criação de um plano de conscientização nacional sobre o aborto seguro).

\section{Referências}

ARTICLE 19. Breve panorama sobre aborto legal e transparência no Brasil. São Paulo, 2018. Disponível em: <https://artigo19.org/wpcontent/blogs.dir/24/files/2018/12/AbortoLegalTranspare\%cc\%82ncia_Reduzido.pdf $>$. Acesso em: 28 jul. 2019.

ARTICLE 19. Mapa Aborto Legal. Brasil, 2019. Disponível em: $<$ https://mapaabortolegal.org/>. Acesso em: 29 jul. 2019.

BRASIL. Decreto-lei No 2.848, de 7 de dezembro de 1940. Código Penal. Diário Oficial da União, 31 de dezembro de 1940.

BRASIL. Ministério da Saúde. Hospitais e serviços de referência em atendimento para mulheres e adolescentes em situação de violência sexual-Brasil [internet]. 2009 [acessado 2015 maio 1]. Disponível em: http:// portal.saude.gov.br/portal/arquivos/pdf/atsm_res_ serv_At_viol_sexual_2009.pdf. 
BRASIL. Supremo Tribunal Federal. $A D P F n^{o} 347 M C / D F$, Rel. Min. Marco Aurélio. 2015.

CAMPOS, Carlos Alexandre de Azevedo. O Estado de Coisas Inconstitucional e o litígio estrutural. In: Revista Consultor Jurídico. Disponível em: $<$ http://www.conjur.com.br/2015-set01/carlos-campos-estado-coisas-inconstitucionallitigio-estrutural>. Acesso em 29 de jul. 2019.

CECATTI, José Guilherme; et al. Aborto no Brasil: um enfoque demográfico. Revista Brasileira de Ginecologia e Obstetrícia. 2010. Disponível em: < http://www.scielo.br/scielo.php?pid=S0100$72032010000300002 \&$ script=sci_abstract\&tlng=pt>. Acesso em 29 jul. 2019.

CERQUEIRA, Daniel; COELHO, Danilo de Santa Cruz. Estupro no Brasil: uma radiografia segundo os dados da Saúde. Brasília: Instituto de Pesquisa Econômica Aplicada, 2014.2 Disponível em <http://www.ipea.gov.br/portal/images/stories/PDFs/nota_tecnica/140327_notatecnicadie st11.pdf $>$. Acesso em 28 jul. 2019.

COLÔMBIA. Corte Constitucional da Colômbia. Sentencia ST - 025, de 22/01/2004. Disponível em: < http://www.corteconstitucional.gov.co/relatoria/2004/T-025-04.htm >. Acesso em 29 jul. 2019.

DINIZ, Débora; MEDEIROS, M. Aborto no Brasil: uma pesquisa domiciliar com técnica de urna. Ciência \& Saúde Coletiva, Rio de Janeiro, v. 15, suppl. 1, p. 959-966. jan./jun. 2010. Disponível em: <http://www.scielo.br/scielo.php?script=sci_arttext\&pid=S1413$81232010000700002>$. Acesso em 29 jul. 2019.

DINIZ, Débora; MEDEIROS, Marcelo; MADEIRO, Alberto. Pesquisa Nacional de Aborto 2016. Ciência e Saúde Coletiva. Vol. 22, n. 2, pp 653-660, 2017. Disponível em: < http://www.scielo.br/scielo.php?pid=S1413-

$81232017000200653 \&$ script=sci_abstract\&tlng=pt>. Acesso em 29 jul. 2019.

DINIZ, Débora; et al. A verdade do estupro nos serviços de aborto legal no Brasil. Revista Bioética (impresso). 2014, vol.22, n.2, pp 291-298. Disponível em: < http://www.scielo.br/pdf/bioet/v22n2/11.pdf>. Acesso em 28 jul. 2019. 
FERNANDES, Marcela. Aborto no Brasil: Como os números sobre abortos legais e clandestinos contribuem no debate da descriminalização. HUFFPOST BRASIL. 19 nov. 2018. Disponível em: <https://www.huffpostbrasil.com/2018/07/31/aborto-no-brasil-comoos-numeros-sobre-abortos-legais-e-clandestinos-contribuem-no-debate-dadescriminalizacao_a_23486575/>.Acesso em: 28 jul. 2019.

MADEIRO, Alberto Pereira; DINIZ, Debora. Serviços de aborto legal no Brasil - um estudo nacional. Ciênc. saúde coletiva [online]. 2016, vol.21, n.2, p.563-572. ISSN 14138123. Disponível em: < http://www.scielo.br/pdf/csc/v21n2/1413-8123-csc-21-02-0563.pdf>. Acesso em: 29 jul. 2019.

MARTINS, Eunice Francisca, et al. Causas múltiplas de mortalidade materna relacionada ao aborto no Estado de Minas Gerais, Brasil, 2000-2011. Cadernos de Saúde Pública. 2017, vol 33, n.1. pp.1-11. Disponível em: < http://www.scielo.br/scielo.php?pid=S0102311X2017000105009\&script=sci_abstract\&tlng=pt>. Acesso em 29 jul. 2019..

MESCE, D.; SINES, E.. Unsafe Abortation: facts \& figures. Washington, DC: Population Reference Bureau; 2006.

ORGANIZAÇÃO DAS NAÇÕES UNIDAS. Relatório da Conferência Internacional sobre População e Desenvolvimento. Cairo, 1994.

PESSOA, Gabriela Sá. Mulheres têm que viajar a São Paulo por aborto legal. Folha de São Paulo, 23 de fevereiro de 2019. Disponível em: $<$ https://www1.folha.uol.com.br/cotidiano/2019/02/mulheres-tem-que-viajar-a-sao-paulopor-aborto-legal.shtml>. Acesso em: 28 jul. 2019.

ROSENDA, Kamila Rodrigues. A declaração de estado de coisas inconstitucional na ADPF 347 e o princípio da separação de poderes. In: FERREIRA, Pedro Paulo da Cunha; CARVALHO, Thiago Ribeiro de. Questões atuais do direito brasileiro e a jurisprudência do STF. Rio de Janeiro: Lumen Juris, 2017.

SOARES, Gilberto Santos. Profissionais de saúde frente ao aborto legal no Brasil: desafios, conflitos e significados. Cadernos de Saúde Pública. Rio de Janeiro. vol. 19, n.2, pp. 399406, 2003. Disponível em < http://www.scielo.br/scielo.php?pid=S0102311X2003000800021\&script=sci_abstract\&tlng=pt>. Acesso em: 29 jul. 2019. 
SOUZAS, Raquel; et al. Aborto e saúde pública no Brasil: reflexões sob a perspectiva dos direitos humanos. Revista Saúde em Debate. Vol. 37, n.98, pp. 504-515. jul/set 2013. Disponível em $<$ http://www.scielo.br/scielo.php?script=sci_arttext\&pid=S0103$11042013000300014>$. Acesso em: 29 jul. 2019.

TALIB, Rosangela Aparecida; CITELI, Maria Teresa. Dossiê: serviços de aborto legal em hospitais públicos brasileiros (1989-2004). São Paulo: Católicas pelo Direito de Decidir, 2005. Disponível em < http://catolicas.org.br/wp-content/uploads/2005/01/CadernoDossieAbortoLegal.pdf>. Acesso em: 27 jul. 2019.

WORLD HEALTH ORGANIZATION. World health report 2005: make every mother and child count. Geneva: WHO; 2005.

Recebido em agosto de 2019. Aprovado em dezembro de 2019. 